\title{
Nitrogen dioxide exposure impairs the frequency of the mucociliary activity in healthy subjects
}

\author{
R. Helleday*, D. Huberman**, A. Blomberg*, N. Stjernberg+, T. Sandström*
}

Nitrogen dioxide exposure impairs the frequency of the mucociliary activity in healthy subjects. R. Helleday, D. Huberman, A. Blomberg, N. Stjernberg, T. Sandström. CERS Journals Ltd 1995.

ABSTRACT: In previous studies, we have reported bronchoalveolar lavage (BAL) findings following single and repeated exposures to $\mathrm{NO}_{2}$. Here, we present the first data on measurements of the frequency of the mucociliary activity in healthy subjects following exposure to $\mathrm{NO}_{2}$.

Twenty four healthy nonsmoking volunteers underwent fibreoptic bronchoscopy, during which mucociliary activity was measured using an in vivo method based on a two-way fibreoptic system, to obtain baseline data. Two weeks later, the subjects were reinvestigated following $\mathrm{NO}_{2}$ exposure. Eight volunteers were investigated 45 min after a 20 min exposure to $1.5 \mathrm{ppm} \mathrm{NO}$ (Group A); eight subjects 45 min after a 20 min exposure to $3.5 \mathrm{ppm} \mathrm{NO}$ (Group B); and eight subjects $24 \mathrm{~h}$ after a $4 \mathrm{~h}$ exposure to $3.5 \mathrm{ppm} \mathrm{NO}$ (Group C).

No activity was detected in Group A or B 45 min after exposure, in contrast to the easily identifiable mucociliary activity waves at the reference bronchoscopy. In group $\mathrm{C}$, a significant elevation of the frequency of the mucociliary activity waves was seen at $24 \mathrm{~h}$.

It is concluded that short-term exposure to $\mathrm{NO}_{2}$ in man produces a significant reduction in the mucociliary activity $\mathbf{4 5} \mathrm{min}$ after exposure. The effect ceases within $24 \mathrm{~h}$. Further studies are needed to evaluate the effects of repeated exposures with $\mathrm{NO}_{2}$ on mucociliary activity in man.

Eur Respir J., 1995, 8, 1664-1668.
*Dept of Pulmonary Medicine and Allergology, University Hospital of Northern Sweden, Umeå, Sweden. **Dept of Lung Medicine, University Hospital, Lund, Sweden. +National Institute of Occupational Health, Medical Division, Umeå, Sweden.

\section{Correspondence: T. Sandström}

Dept of Pulmonary Medicine and Allergology University Hospital of Northern Sweden S-901 85 Umeå

Sweden

Keywords: Air pollution

cilia

human

in vivo

lung

mucociliary clearance

nitrogen dioxide

Received: November 211994

Accepted after revision July 101995
Nitrogen dioxide $\left(\mathrm{NO}_{2}\right)$ is one of the most common air pollutants. $\mathrm{NO}_{2}$ is mainly produced by various combustion processes, especially in industrial locations and urbanized areas, but also in homes with gas stoves. In the European countries, the exposure limits for an $8 \mathrm{~h}$ workshift range $2-5 \mathrm{ppm}\left(5-9 \mathrm{mg} \cdot \mathrm{m}^{-3}\right)$. Concentrations up to the exposure limit for $\mathrm{NO}_{2}$ are frequently found in indoor air in certain industries. Epidemiological studies indicate increased susceptibility to airway infections due to $\mathrm{NO}_{2}$ exposure [1-3]. This is supported by in vitro and animal studies $[4,5]$. Experimental studies in humans using fibreoptic bronchoscopy and bronchoalveolar lavage (BAL) have demonstrated the acute airway inflammation caused by single exposure to $\mathrm{NO}_{2}$ [6-8]. One experimental study in humans has indicated potentially detrimental effects of $\mathrm{NO}_{2}$ on immune competent cells, with reduced alveolar macrophage killing of virus after a single exposure [9]. Furthermore, repeated exposures every second day have been reported to decrease bronchoalveolar cytotoxic lymphocyte subsets $[10,11]$.

The aim of the present study was to investigate whether exposure to $\mathrm{NO}_{2}$ in workroom concentrations would affect the frequency of the mucociliary activity in healthy humans. The experimental protocol was based on previous studies by this group $[6,7]$.
Subjects and methods

\section{Subjects}

Twenty four healthy nonsmoking subjects, 14 males and 10 females, with no history of asthma or other respiratory illness, volunteered for the study. All subjects were free of airway infections 6 weeks before and during the study. The mean age was 27 yrs (range 23-30 yrs). The study was approved by the Ethics Committee of the University of Umeå, Sweden.

\section{Design of the study}

All subjects underwent fibreoptic bronchoscopy twice, with recording of the frequency of the mucociliary activity. Initially, bronchoscopy was conducted to obtain baseline data, and at least 2 weeks later the subjects were reinvestigated following an $\mathrm{NO}_{2}$ exposure. Hence, each subject served as his or her own control. Eight volunteers were investigated $45 \mathrm{~min}$ after a $20 \mathrm{~min}$ exposure to $1.5 \mathrm{ppm} \mathrm{NO}_{2}$, eight subjects after a $45 \mathrm{~min}$ exposure to $3.5 \mathrm{ppm} \mathrm{NO}$, and eight subjects $24 \mathrm{~h}$ after a $4 \mathrm{~h}$ exposure to $3.5 \mathrm{ppm} \mathrm{NO}_{2}$. 
The exposures were conducted in an exposure chamber, according to a previously described protocol [6], with a moderate workload of $75 \mathrm{~W}$ on a bicycle ergometer for 15 min during the $4 \mathrm{~h}$ exposure.

\section{Fibreoptic bronchoscopy}

Atropine $0.50-0.75 \mathrm{mg}$ was given subcutaneously 45 min before bronchoscopy. No complementary medication for sedation was used. The fibreoptic bronchoscope was introduced through the mouth with the subject in the supine position. Local anaesthesia was obtained with lidocaine sprayed in the mouth and pharynx and instilled with a syringe in the larynx and upper trachea. After the bronchoscope had been inserted in the trachea, lidocaine was given solely from a position at the right side of the mid-trachea and directed towards the orifice of the right main bronchus. No lidocaine was introduced towards the right upper lobe to prevent any effects on the mucosal area chosen for measurement. The same procedure was used in all bronchoscopies.

\section{Measurement of mucociliary activity}

The frequency of mucociliary activity was measured according to a recently described technique [12]. Briefly, light is emitted from a cold light source (LED, Stanley $\mathrm{H}-2 \mathrm{~K}$ ) with a wavelength of $660 \mathrm{~nm}$ generated in a tension-stabilizing unit and then led through a glass-fibre. The light is emitted from the end of the fibre and the reflected light is received by a parallel glass-fibre. Both fibres are glued together in a catheter $(2.6 \mathrm{~mm}$ diameter and length $960 \mathrm{~mm}$ ), which can be inserted through the work channel of a fibreoptic bronchoscope (Olympus BF 1T10). The emitted light is reflected on the viscous mucous surface overlying the cilia. Fluctuations in the light intensity by the altered reflexes due to the beatings of the cilia are picked up by the second glass-fibre and transmitted back to the recording unit. The fluctuations are then converted to voltage amplitude changes as measured by a photo diode, amplified, filtered (Krohn-Hite filter $3550,0-30 \mathrm{~Hz}$ ) and finally recorded by an ink writer (Mingograf 34, Elema Schönander) (fig. 1).

The measurement was performed with a fibre-catheter approximately 4-5 $\mathrm{mm}$ from the bronchial wall area selected, with the patient holding his/her breath during the procedure. The carina or the subsegmental carinae of the right upper lobe were selected. By selecting the bronchi least affected by the movements caused by the cardiac contractions, optimal recording conditions were obtained. It was carefully ensured that the tip of the bronchoscope and the catheter were never in contact with the unanaesthetized mucosal surface. A minimum of five measurement periods of 20-30 s each were performed.

During the measurement procedure, one investigator manually adjusted the amplification of the signals recorded from the reflected light, to optimize the reading of the wave pattern. With the help of a simultaneous electrocardiographic (ECG) recording, the rhythmic waves

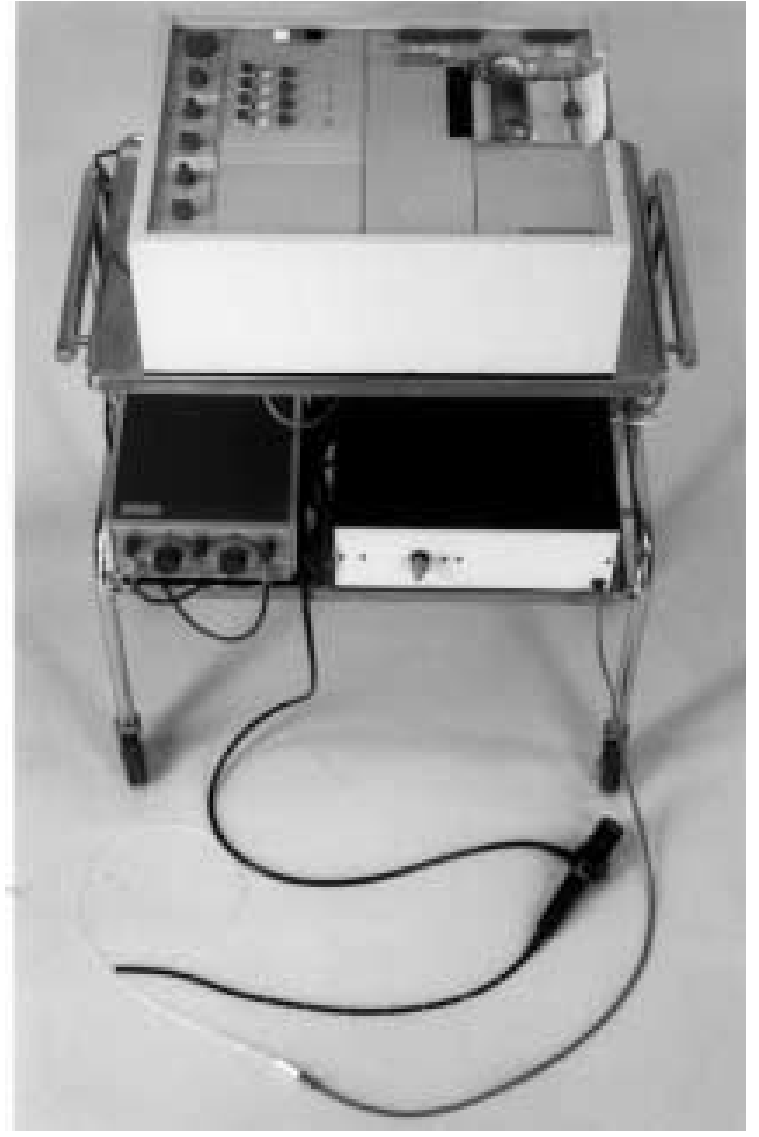

Fig. 1. - The recording unit with fibreoptic bronchoscope and the glass fibre cable, light source, filter and ink jet writer.

caused by the heart beats were easily identified. The investigator then tuned the amplification in order to identify the rhythmic mucociliary activity wave pattern.

Mucociliary activity waves were detected as waves with a constant wave-to-wave interval, which were superimposed on the basal rhythmic wave pattern caused by the cardiac contractions. Thus, two independent wave patterns were added to each other. The mucociliary activity waves were easily identified, not only during the intervals between the heart beat waves but also as waves superimposed on top of the heart beat waves (fig. 2).

It should be noted that the size of the waves recorded on the printer is not necessarily correlated with the amplitude or "strength" of the mucociliary activity, but is dependent on the angle between the cilia and the emitted light, as well as the manually adjusted amplification of the signals.

When no mucociliary activity was identified, at least three different mucosal areas were investigated with multiple measurements, with different angles of the light emitting catheter, at each site. Up to five recordings were added to the minimum of five recordings commonly used. This thoroughly performed examination was intended to minimize the risk of missing any identifiable mucociliary activity.

The frequency of the mucociliary activity waves was calculated manually on the print-out. The mean of at least two well performed measurements with less than 
Baseline

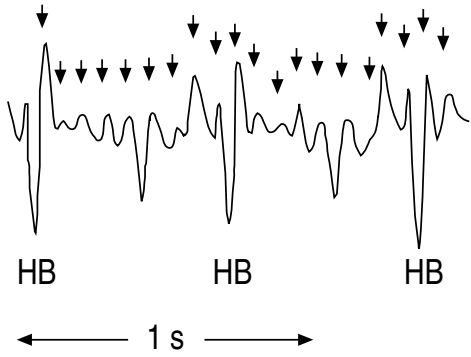

After $\mathrm{NO}_{2}$ exposure

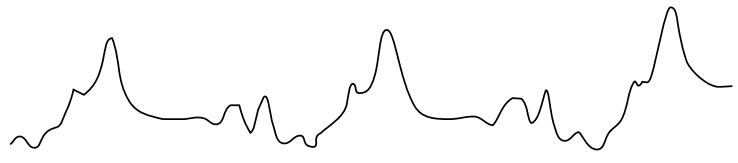

HB
HB

Fig. 2. - Left - easily identified mucociliary activity waves (arrows) overlaying heart beat waves recorded at the baseline bronchoscopy. Right - symmetric pattern of heart beat $(\mathrm{HB})$ waves without any interference by mucociliary activity waves recorded 45 min after 3.5 ppm $\mathrm{NO}_{2}$ for 20 min in the same subject.

Table 1. - Mucociliary activity before and after exposure to $\mathrm{NO}_{2}$

\begin{tabular}{|c|c|c|c|}
\hline Mucociliary activity $\mathrm{Hz}$ & Group A & Group B & Group C \\
\hline Before exposure & $\begin{array}{c}13.4 \pm 1.0 \\
(12.0-15.0)\end{array}$ & $\begin{array}{l}13.4 \pm 0.6 \\
(13.0-14.5)\end{array}$ & $\begin{array}{c}12.4 \pm 0.9 \\
(12.0-14.5)\end{array}$ \\
\hline After exposure & $\begin{array}{c}0 \pm 0 \\
(0-0)\end{array}$ & $\begin{array}{c}0 \pm 0 \\
(0-0)\end{array}$ & $\begin{array}{c}13.8 \pm 0.8 \\
(13.0-15.5)\end{array}$ \\
\hline p-value* & $<0.001$ & $<0.001$ & $<0.05$ \\
\hline
\end{tabular}

Values are presented as mean $\pm \mathrm{SD}$, and range in parenthesis. Group A: $1.5 \mathrm{ppm} \mathrm{NO}$ for 20 min, recording 45 min after exposure; Group B: $3.5 \mathrm{ppm} \mathrm{NO}$ for $20 \mathrm{~min}$, recording $45 \mathrm{~min}$ after exposure; Group C: $3.5 \mathrm{ppm} \mathrm{NO}$ for $4 \mathrm{~h}$, recording $24 \mathrm{~h}$ after exposure. *: Student's t-test for paired observations.

$10 \%$ intervariability were calculated independently by two different investigators, unaware of whether the measurements had taken place before or after exposure to $\mathrm{NO}_{2}$.

All through the investigation, pre- and postexposure measurements were "mixed" when interpreting the printouts, ensuring that no shift of methodology could influence the results.

\section{Statistics}

Student's t-test for paired observations was used. A p-value of less than 0.05 was considered significant.

\section{Results}

Satisfactory measurement conditions were obtained at all bronchoscopies. Table 1 shows the wave frequency values (mean \pm SD and interval) before and after the three exposure regimens. Forty five minutes after a $20 \mathrm{~min}$ exposure to 1.5 and $3.5 \mathrm{ppm} \mathrm{NO} \mathrm{N}_{2}$ (Groups $\mathrm{A}$ and $\mathrm{B}$ ), no mucociliary activity was detected in the measurements from any subject $(\mathrm{p}<0.001$, respectively). This contrasts to the easily identifiable mucociliary activity waves ranging $12-15 \mathrm{~Hz}$ recorded under baseline conditions. Twenty four hours after a $4 \mathrm{~h}$ exposure to $3.5 \mathrm{ppm}$ (Group C), no subject showed any pronounced decrease in mucociliary activity. Instead, there was a significant elevation in the mucociliary activity wave frequency $(\mathrm{p}<0.05)$ compared with the measurement before exposure.

\section{Discussion}

This study, as well as a recent methodology paper [12], demonstrates that the two-way fibreoptic system, mounted within a catheter inserted through the bronchoscope work channel, is technically uncomplicated and easy to employ. The mucociliary activity, in terms of frequency of the mucociliary activity waves, was highly homogenous between the subjects under baseline conditions before exposure (range 12-15 Hz). This is in accordance with a recent in vivo study in humans [12]. In several in vitro studies similar results $(11-13 \mathrm{~Hz})$ have been obtained both in humans [13,14] and animals [15]. Some in vitro studies of human cultured epithelial cells have, however, reported far lower frequencies, which may have been due to in vitro situations that do not sufficiently conform with the normal physiological environment in vivo $[16,17]$.

To the best of our knowledge, this is the first report regarding the frequency of the mucociliary activity in vivo following $\mathrm{NO}_{2}$ exposure in humans. The present study demonstrates pronounced changes in the mucociliary activity pattern in all subjects $45 \mathrm{~min}$ after a 20 min exposure to either 1.5 or $3.5 \mathrm{ppm} \mathrm{NO}_{2}$, concentrations often found in industrial workrooms.

We suggest these possible explanations for the pronounced decline observed in the mucociliary activity: the findings could represent dyskinesia, unco-ordinated ciliary beat direction, which would give rise to asynchronous light reflections that could be interpreted as absence of mucociliary activity [18-20]. It seems less likely that an acute complete ciliostasis would have occurred, since the activity had recovered within $24 \mathrm{~h}$. Whatever the 
explanation may be, the mucociliary activity appears to be severely disturbed.

We believe that the observed effects represent a disturbed mucociliary activity due to toxic effects of the strong oxidant and free radical properties of $\mathrm{NO}_{2}$. It has been suggested that impairment of mucociliary activity may represent the earliest detectable sign of lung injury [21], and the observed effects on ciliary activity could therefore be an additional disadvantageous contribution to the acute inflammation, previously shown in the airways, following $\mathrm{NO}_{2}$ exposure [6-8]. The decrease in the ciliary activity seems to be time-limited, as the impairment had ceased $24 \mathrm{~h}$ after a prolonged exposure to 3.5 ppm $\mathrm{NO}_{2}$ for $4 \mathrm{~h}$. The rationale for the $4 \mathrm{~h}$ exposure duration at $3.5 \mathrm{ppm} \mathrm{NO}_{2}$ was that this was close to maximally occurring work room exposure, and a negative finding $24 \mathrm{~h}$ after such an exposure rules out that $\mathrm{NO}_{2}$ may cause long term persisting effects on mucociliary activity. The modest increase in mucociliary activity after $24 \mathrm{~h}$ is indeed small and within the normal range. However, it cannot be excluded that this could represent a possible counter response to the earlier decrease in the activity. Exposure to $\mathrm{NO}_{2}$ has been associated with increased susceptibility to airway infections [1-5], and an immune suppressive effect of $\mathrm{NO}_{2}$ has been suggested in a number of experimental studies [9-11, 22]. Although the duration of the observed decline in mucociliary activity is not presently known, the effects observed may potentially facilitate the ability of microorganisms or allergens to interact with the airways. This could be of importance to sensitive people, such as asthmatics, exposed to these $\mathrm{NO}_{2}$ concentrations in industrial work environments, although the effects of $\mathrm{NO}_{2}$ are dependent on multifactorial events within the airways.

Earlier in vitro studies on human epithelial cells have not produced consistent data on the effects of $\mathrm{NO}_{2}$ on beat frequency. In a report from Devalia et al. [23], cultured human bronchial epithelial cells were exposed to air or $0.1-2.0 \mathrm{ppm} \mathrm{NO}_{2}$ for $20 \mathrm{~min}$, and the ciliary beat frequency was measured $1 \mathrm{~h}$ afterwards. The authors found a decrease in the frequencies, but the attenuation was only significant at the highest concentration. This in vitro data is not fully comparable with the present results, since the beat frequencies were only expressed as $\%$ attenuation from baseline and not in beats per second. However, the tendency of the $\mathrm{NO}_{2}$ effects were the same as in the present study. Divergent results were reported by KIENAST et al. [24], who found $\mathrm{NO}_{2}$ exposure caused an increase in ciliary beat frequency in vitro.

At the present time, human results cannot be compared with animal data due to the differences in species and study designs. The animal studies have regularly been performed with repeated exposures. In these studies, only exposure to very high concentrations of $\mathrm{NO}_{2}$ has been found to affect ciliary beat frequency and decrease the mucociliary transport rate [21]. Long-term exposures to high concentrations of $\mathrm{NO}_{2}$, for example exposure to $\geq 6$ ppm $\mathrm{NO}_{2}$ for 6 weeks, tend to reduce mucociliary clearance $[25,26]$. SCHLESINGER et al. [27] were unable to find any reduction of mucociliary clearance in rabbits exposed to 0.3 or $1 \mathrm{ppm} \mathrm{NO}_{2}$ for $2 \mathrm{~h} \cdot \mathrm{day}^{-1}$ for up to 14 days.
According to our experience, the right upper lobe is the most suitable part of the human airways for measurement of the frequency of the mucociliary activity waves in vivo [12]. Firstly, the bronchoscope has great availability to the right upper lobe. Secondly, the anatomical circumstances prevent unwanted spillage towards the upper lobe cristae, when local anaesthetics are instilled in the trachea. Thirdly, the interference of the heart movements in the measurements are kept to a minimum. The bronchoscope per se limits the physical possibility of evaluating more peripheral airways in the bronchial tree.

A technical question of interest is whether the measurements in the right upper lobe were representative of the whole bronchial tree. No data are presently available regarding the mucociliary activity at the same subsegmental levels in different lobes. This question was not addressed in the present investigation, but is of interest to clarify in forthcoming studies.

It is concluded that short-term exposure to $\mathrm{NO}_{2}$ in normal healthy volunteers gives a significant reduction in the mucociliary activity $45 \mathrm{~min}$ after exposure. The effect ceases within $24 \mathrm{~h}$ but could potentially be of importance in the mucociliary clearance of for example allergens, viruses or other microorganisms. Further studies are needed to evaluate the importance of the present findings.

Acknowledgements: The authors wish to thank E. Ädelroth for valuable criticism, H. Burström for technical support and A. Bergström for typing assistance.

\section{References}

1. Lindvall T. Health effects of nitrogen dioxide and oxidants. Scand J Work Environ Health 1985; 11 (Suppl. 3): $10-28$

2. Samet JM. Nitrogen dioxide and respiratory infection. Am Rev Respir Dis 1989; 139: 1073-1074.

3 Jakab GJ. Nitrogen dioxide-induced susceptibility to acute respiratory illness: a perspective. Bull NY Acad Med 1981; 56: 847-855.

4. Jakab GJ. Modulation of pulmonary defense mechanisms by acute exposures to nitrogen dioxide. Environ Res 1987; 42: 215-228.

5. Davis JK, Davidsson MK, Schoeb TR, Lindsey JR. Decreased intrapulmonary killing of Mycoplasma pulmonis after short-term exposure to $\mathrm{NO}_{2}$ is associated with damaged alveolar macrophages. Am Rev Respir Dis 1992; 145: 406-411.

6. Sandström T, Andersson M-C, Kolmodin-Hedman B, Stjernberg N, Ängström T. Bronchoalveolar mastocytosis and lymphocytosis after nitrogen dioxide exposure in man: a time-kinetic study. Eur Respir J 1990; 3: $138-143$.

7. Sandström T, Stjernberg N, Andersson M-C, et al. Inflammatory cell response in bronchoalveolar lavage fluid after nitrogen dioxide exposure of healthy subjects: a dose-response study. Eur Respir J 1991; 3: 332-339.

8. Frampton MW, Finkelstein JN, Roberts NJ, Smeglin AM, Morrow PE, Utell MJ. Effects of nitrogen dioxide exposure on bronchoalveolar lavage proteins in humans. Am J Respir Cell Mol Biol 1989; 1: 499-505. 
9. Frampton MW, Smeglin AM, Roberts NJ, Finkelstein JN, Morrow PE, Utell MJ. Nitrogen dioxide exposure in vivo and human alveolar macrophage inactivation of influenza virus in vitro. Environ Res 1989; 48: 179-192.

10. Sandström T, Ledin M-C, Thomasson L, Helleday R, Stjernberg N. Reductions in bronchoalveolar lymphocyte subpopulations following repeated exposure to 1.5 ppm nitrogen dioxide. Br J Ind Med 1992; 49: 850-854.

11. Sandström T, Helleday R, Stjernberg N, Bjermer L. Effects of repeated exposure to $4 \mathrm{ppm}$ nitrogen dioxide on bronchoalveolar lymphocyte subsets and macrophages in healthy men. Eur Respir J 1992; 5: 1092-1096.

12. Huberman D. Device for measuring mucociliary activity in the human bronchi during fibreoptic bronchoscopy. Acta Otolaryngol 1993; 113: 683-686.

13. O Callaghan C, Altherton M, Karim K, et al. The effect of halothane on neonatal ciliary beat frequency. J Paediatr Child Health 1994; 30(5): 429-431.

14. Veale D, Glasper PN, Cascoigne A, Dark JH, Gibson GJ, Corris PA. Ciliary beat frequency in transplanted lungs. Thorax 1993; 48: 629-631.

15. Joki S, Saano V. Ciliary beat frequency at six levels of the respiratory tract in cow, dog, guinea-pig, pig, rabbit and rat. Clin Exp Pharmacol Physiol 1994; 21(5): 427-434.

16. Wong LB, Miller IF, Yeates DB. Regulation of ciliary beat frequency by autonomic mechanisms in vitro. $J$ Appl Physiol 1988; 65: 1895-1901.

17. Rusznak C, Devalia JL, Sapsford RJ, Davies RJ. Circadian rhythms in ciliary beat frequency of human bronchial epithelial cells, in vitro. Respir Med 1994; 88: 461463.
18. Hilding AC. Ciliary streaming in the bronchial tree and the time element in carcinogenesis. N Engl J Med 1957; 256: 634

19. Iravani J. Mucociliary abnormalities underlying impaired mucus elimination. Bull Physiopathol Respir(Nancy) 1975; 9: 397.

20. Van As A, Webster I. The morphology of mucus in mammalian pulmonary airways. Environ Res 1974; 7: 1.

21. Wanner A. Clinical aspects of mucociliary transport. Am Rev Respir Dis 1977; 115: 73-125.

22. Folinsbee LJ. Human health effects of air pollution. Environ Health Perspect 1992; 100: 45-56.

23. Devalia JL, Sapsford RJ, Cundell DR, Rusznak C, Campbell AM, Davies RJ. Human bronchial epithelial cell dysfunction following in vitro exposure to nitrogen dioxide. Eur Respir J 1993; 6: 1308-1316.

24. Kienast K, Riechelmann H, Knorst M, Müller-Quernheim J, Ferlinz R. Dose dependent effects of $\mathrm{SO}_{2}$ and $\mathrm{NO}_{2}$ on human ciliary beat frequency. Am Rev Respir Dis 1993; 147: A389.

25. Giordano AM, Morrow PE. Chronic low-level nitrogen dioxide exposure and mucociliary clearance. Arch Environ Health 1972; 25: 443-449.

26. Dalham T, Sjöholm J. Studies on $\mathrm{SO}_{2}, \mathrm{NO}_{2}$, and $\mathrm{HN}_{3}$ : effect on ciliary activity in rabbit trachea of single in vitro exposure and resorption in rabbit nasal cavity. Acta Physiol Scand 1963; 58: 287-291.

27. Schlesinger RB, Driscoll KE, Vollmuth TA. Effect of repeated exposures to nitrogen dioxide and sulphuric acid mist alone or in combination on mucociliary clearance from the lungs of rabbits. Environ Res 1987; 44(2): 294-301. 